\title{
A Study of the Effect on Trust and Attitude with Online Shopping
}

\author{
Tsung-Li Wang \\ Department of Animation and Game Design \\ Shu-Te University \\ Kaohsiung, Taiwan
}

\author{
Ya Fen Tseng \\ Dept. of Information Management Chung \\ Hwa University of Medical Technology \\ Tainan, Taiwan
}

\begin{abstract}
While on-line shopping is considered as a special type of e-service, the adoption rate of this service in Taiwan has been paid attention recently. The initial adoption of on-line shopping is the important driving force to further influence the use and continued use of this service. The model of Trust and technology acceptance model (TAM) in Gefen et al. [1] has been well studied in on-line shopping and showed that understanding both the Internet technology and trust issue is important in determining behavioral intention to use. The model of Trust in Wu and Chen [2] has been well discussed the consumer intention in on-lion tax. An extension of Trust and Attitude with TAM model would be in more comprehensive manner to understand behavioral intention to use online shopping. Furthermore, a large sample survey is used to empirically examine this framework.
\end{abstract}

Keywords-trust; attitude; technology acceptance model (TAM)

\section{Introduction}

Customer service is a series of activities designed for resolving purchasing problems that customers encounter throughout the product life cycle to enhance customer satisfaction. When customer service is supplied over the Internet, sometimes automatically, it is referred to as e-service. In general, e-service could include customer service as part of on-line shopping and pure-play service offered in e-commerce. Initially, on-line consumers did not demand high levels of customer services and the Internet service was fairly basic such as online catalogue, on-line transaction, and order fulfillment. However, on noticing the Internet bubble burst and the profit gained from e-commerce far away from marketer expectations, business managers began to search the new potency of ecommerce. They found that the key to success in the Internet era is mainly attributed to the ability of providing customers with better service to attract and retain customers, and eventually, building a long-term relationship with customers.
For advocating users' behavior toward the initial adoption of on-line shopping, system developers thus require first understanding their real needs and expectations in order to offer more favorable services. In fact, an understanding of the users' behavior would be fundamentally beneficial to system design of an e-service since it could effectively identify the barriers for designing reference in advance. However, ecommerce is a less verifiable and controllable environment in which online service or transaction is offered without physical face-to-face contact and simultaneous exchange of service $s$ and money. The spatial and temporal separation of e-commerce between customers and evendors as well as the unpredictability of the Internet infrastructure generate an implicit uncertainty around the initial adoption of on-line service [3]. Accordingly, the initial adoption of on-line shopping basically involves the acceptance of both the Internet technology and on-line service providers. As technology acceptance model (TAM) is mainly proposed for technology-based perspective through two system features of perceived usefulness (PU) and perceived ease of use (PEOU) [4], it is incomplete in the context of on-line services.

A model, named Trust and Attitude with TAM, has been previously presented in exploring the acceptance of on-line shopping setting [1]. This model integratively placed use of on-line system into both system features such as ease of use and usefulness and trust in e-vendors. This result indicated that these variables are good predictors for behavior intention to use on-line shopping.

To understand better the customers' purchase intentions, this study proposed a theoretical model that extends the TAM by incorporating trust and attitude dimensions with TAM model. The research questions addressed in this study were:

RQ1. Is trust important determinant of behavior intentions of online shopping with TAM and TPB model?

RQ2. Does trust have a significant influential impact on attitude; perceive behavior control and 
subjective norm in the uncertain online shopping environment?

RQ3. Are perceived usefulness, attitude, perceive behavior control and subjective norm important determinants of behavior intentions of online shopping?

\section{Literature review}

TAM is an adaptation of the theory of reasoned action (TRA) and mainly designed for modeling user acceptance of information technology. This model hypothesizes that system use is directly determined by behavioral intention to use, which is in turn influenced by user's attitude toward using the system and PU of the system. Attitude and PU are also affected by PEOU. PU, reflecting a person's salient belief in using the technology, will be helpful in improving performance. PEOU, explaining a person's salient beliefs in using the technology, will be free of any effort.

The appeal of this model lies in both specific and parsimonious as well as an indication of high prediction power of technology usage. These determinants are also easy to understand for system developers and can be specifically considered during system requirement analysis and other system development stages. These factors are common in technology-usage settings and can be applied widely to solve the acceptance problem.

TPB underlying the effort of TRA has been proven successful in predicting and explaining human behavior across various information technologies. According to TPB, a person's actual behavior in performing certain action is directly influenced by his or her behavioral intention and in turn, jointly determined by attitude, subjective norm and perceived behavioral control toward performing the behavior. Behavioral intention is a measure of the strength of one's willingness to try and exert while performing certain behavior.

The section will discuss the importance of technology acceptance model and online shopping, and the relationship between trust and ecommerce.

\subsection{Technology acceptance model and online shopping value}

The TAM [4, 5] was originally developed to predict users' initial adoption or use of a new IT in the workplace. It posits that user acceptance of can be explained by two salient beliefs: perceived usefulness and perceived ease of use. Perceived usefulness is defined as "the degree to which a person believes that using a particular system would enhance his or her job performance” and perceived ease of use is defined as "the degree to which a person believes that using a particular system would be free of effort" [5]. Perceived usefulness and perceived ease of use are considered instrumental in achieving valued outcomes, and thus reflect the utilitarian or extrinsic aspects of IT usage.

Marketing scholars have argued that the online shopping experience not only produces utilitarian value but also hedonic value [6, 7]. Recently, some studies have applied the TAM in the online shopping and e-commerce contexts with the addition of trust as an important factor, and found that trust has the different effects on customer intention to use online shopping web sites, intention to return, or perceived usefulness. For example, Chiu et al. [8] found that trust has a stronger influence on repurchase intention and perceived usefulness to use online shopping. Wu and Chen [2] found that the trust significantly affects attitude, perceive behavior control, and subjective norm; perceived usefulness, perceived usefulness to use, and trust have a stronger influence on attitude on-line tax. Shin $[9,10]$ found that perceived usefulness and perceived ease of use significantly affect attitude; attitude has a stronger influence on intention of mobile wallet. It appears that the exact nature of the impacts of trust, and attitude on customer purchase intention towards online shopping remains the important factors with TAM model.

\subsection{Trust and ecommerce relationship}

The connections between trust and TAM have been widely discussed in literature in that the relationships between PU, PEOU, and trust are hypothesized in many online-based business settings $[1,3,11]$. In particular, a model of Trust and TAM was well defined in on-line shopping setting [1]. This model explicitly indicated their relationship as trust is an antecedent of PU, PEOU is an antecedent of trust, and trust has a direct influence on behavioral intention to use. Trust is one of the determinants of $\mathrm{PU}$, especially in an on-line environment, because part of the guarantee that consumers will sense the expected usefulness from the web site is based on the sellers behind the web site. Moreover, trust is recognized to have positive effect on PU since trust allows consumers to become vulnerable to e-vendor to ensure that they gain the expected useful interaction and service [3]. While consumers initially trust their e-vendors and have an idea that adopting online service is beneficial to their job performance, they will believe the on-line service is useful [1].

On the other hand, PEOU is hypothesized to have positive influence on trust because PEOU can help promote customers' favorable impression on evendors in the initial adoption of on-line service and further, cause customers to be willing to made investment and commitment in buyer-seller relationship [1, 12]. In general, while following the definition of social cognitive theory, PEOU can be argued to positively influence a person's favorable outcome expectation toward the acceptance of an 
innovative technology [13]. This is because cognition-based trust, as discussed previously, is mainly built on the first impression of a person toward certain behavior and extensively, PEOU in terms of on-line service can be considered the first feeling or expectation established for further continued on-line transaction. In sum, while on-line shopping is considered a special type of e-service, the Trust and TAM model is partly fitted to this online store setting while there are additional variables, as discussed below, to be included in the particular context.

\section{Research model}

While on-line shopping is considered as a special type of e-service, the initial adoption in on-line shopping, in essence, concerns both the roles of the Internet technology and e-vendor in providing service. The Trust and TAM model in Gefen et al. [1] has been well studied in on-line shopping setting and showed that understanding both the Internet technology and trust issue is critical in determining behavioral intention to use on-line shopping, as discussed above. Besides, the diffusion of on-line shopping could also be influenced by the potential antecedents such as individuals, organizational members, and social system while the issue for innovative technology is well discussed in Roger [14]. Trust, perceived ease of use, perceived usefulness and enjoyment are significant positive predictor of customers' repurchase intentions. And privacy has the positive influence on trust in online shopping [8]) and in social networking [10]. According to the research model of Chiu et al. [8] and $\mathrm{Wu}$ and Chen [2], this study explores the research variables including the trust, perceived usefulness (PU), perceived ease of use(PEOU), attitude(AT), and behavior intentions(BI) as the influence on online shopping; and the analysis formula as following. Moreover, this study refers the theory and model such as Gefen et al. [1], Bhattacherjee [15] and Venkatesh and Davis [16, 17] and builds the research framework. An extension of Trust and Attitude with TAM model would be in more comprehensive manner to understand the acceptance behavior toward on-line shopping and hopefully, this extension would provide us with higher explanatory power to examine this problem and effectively improve the usage rate. Furthermore, these hypotheses were further verified for their validity by empirical data (See Figure 1).

H1 : PU has positive effect on intention to sue online shopping.

H2 : AT has positive impact on intention to use online shopping.

H3 : PU has positive impact on attitude to use online shopping.
H4 : PEOU positively influences attitude to use online shopping.

H5 : Trust has positive effect on attitude to use online shopping.

H6 : PEOU has positive impact on PU to use online shopping.

H7 : Trust has positive effect on PU to use online shopping.

H8 : PEOU positively influences trust to use online shopping.

Notes: $\mathrm{PU}=$ perceived usefulness; PEOU= perceived ease of use; $\mathrm{AT}=$ attitude; $\mathrm{BI}=$ behavior intentions

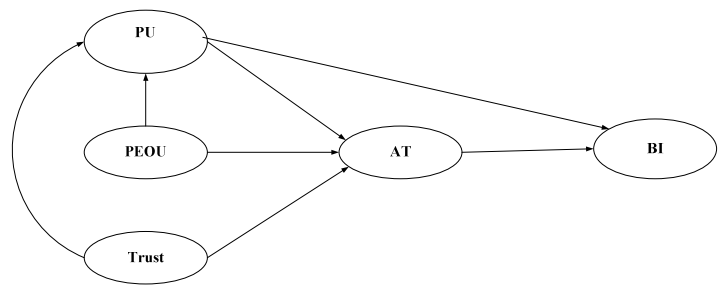

Figure 1. The research framework

\section{Research design}

A large sample survey of on-line shopping declaration was employed to empirically test this research model. The instrument and respondent sample are designed as below.

\subsection{Basic information}

This part of questionnaire is used to collect basic information about respondent characteristics including gender, age, education, occupation, experience (online shopping web), frequency, cost, and product type in online shopping.

\subsection{Perceived usefulness}

This study adopts perceived usefulness as the mediate factor of behavior intention with online shopping. Thus, adopting the four items [16, 17] measures perceived usefulness.

\subsection{Perceived ease of use}

This study adopts perceived ease of use as one mediate factor of behavior intention with online shopping. Thus, adopting the four items [16, 17]measures perceived ease of use.

\subsection{Trust}

Trust items are composed to reflect trust beliefs of citizens in using online shopping. This part of questionnaire is thus adapted from the study [1]. Because the measurement in Gefen et al. [1] is 
originally developed for on-line business and its focus is on customer-seller relationship, therefore, a couple of measuring items concerning market, opportunistic, and honest issues, which are irrelevant to the online shopping, are dropped from the list. After the screen and shortening process, this part comprises three items.

\subsection{Attitude}

Trust and subjective norm influence the behavior intension directly with online shopping. This study adopts four items for measuring attitude [15].

\subsection{Behavior intention}

The relative behavior of privacy and trust influences behavior intention with online shopping such as attitude, subjective norm, trust, and perceive behavior control. This study measures the behavior intention with three items $[16,17]$.

\subsection{Survey administration}

The research model was tested with data from facebook, purk, and puzze with online shopping customers. Facebook, purk, and puzze with online shopping were chosen because it is the most widely used online store in Taiwan. The data for the study were collected via a web survey. A web-based questionnaire was used for three reasons. First, it was possible to reach a large number of potential subjects and give them instant access to the questionnaire, in turn, obtaining more representative results. Second, it offered an economical, reliable method for gathering empirical data [18]. Third, a web survey is consistent within the context of this study, which focuses on the usage of online shopping.

The number of surveys completed was 206. And, all customers had the experience with online shopping, we adopted the items associated with online shopping in the responsiveness scale. The exclusion of questionnaires that indicated no contact experience and invalid ones resulted in 206 valid questionnaires for the data analysis.

Table 1 gives demographic information about the respondents. To give an indication of the representativeness of our sample, we compared it with a nationwide sample of online consumers. The large majority of our samples was male (63.6\%); the most age of our sample are between 20 to 40 years old; the most education level came from university; the most occupation was the students. Our samples often use the online store such as Yahoo and Pchome about one or three months. Then, our sample always cost about NT500 to 1000 for the electronic product one time.

\section{Data analysis}

Structural equation modelling (SEM) was used to analyse the data for three reasons. First, SEM is a multivariate technique that permits the simultaneous estimation of multiple equations. Second, SEM performs factor analysis and regression analysis in one step, as SEM is used to test a structural theory. Third, SEM has become a very popular technique in the social sciences based on its main strengths.

A structural equation modeling analysis was performed using partial least squares (PLS; PLSGraph 3.0). PLS provides an analysis of both a measurement model and a structural model, and allows latent constructs to be modeled as reflective or formative indicators. For the model tested, all constructs were modeled as reflective.

\subsection{Measurement model}

First, content validities should be relatively acceptable since the various parts of questionnaire were all adapted from the literature and have been reviewed carefully by practitioners. Next, confirmatory factor analysis in Lisrel software was used to analyse construct validities, basically the analytical procedure including three stages as described below. First, a measurement model should be assessed for goodness-of-fit. The literature suggested that, for a good model fit, chi-square/ degrees of freedom ( $\left.\chi^{2} / d f\right)$ should be less than 3 , adjusted goodness-of-fit index (AGFI) should be larger then 0.8 , goodness-of-fit index (GFI), normed fit index (NFI), and comparative fit index (CFI) should all be greater than 0.9 , and root mean square error (RMSE) should be less than 0.10. Second, convergent validity is assessed by three criteria. Item loading $(\lambda)$ is at least 0.7 and significant, composite construct reliability is a minimum of 0.8 , and average variance extracted (AVE) for a construct is larger than 0.5 . Finally, discriminant validity is assessed by the measure that the AVE of each construct should be larger than its square correlation with other constructs.

The indices for the measurement model indicate a good fit with $\chi^{2} / d f$ (488.321/296), AGFI (0.81), GFI (0.86), NFI (0.96), CFI (0.99), and RMSE (0.05). Thus, this measurement model indicates a high degree of reliability as well as convergent and discriminant validities.

\subsection{Structural model}

The technique of structured equation modeling was used to examine the causal structure of the proposed model in this study. The evaluation of this research model can be carried out in three steps. 
First, a GFI for the structural model was examined as the same GFIs applied in assessing the measurement model. Second, the standardized path coefficients and their statistical significance for the hypotheses in this model were estimated. Finally, as a measure of the entire structural equation, an overall coefficient of determination $\left(\mathrm{R}^{2}\right)$ was calculated, similar to that found in multiple regression analysis. The testing results of GFIs are all under the acceptable levels with, $\chi^{2} / d f(540 / 310=1.742)$, AGFI (0.80), GFI (0.84), NFI (0.96), CFI (0.98), and RMSE (0.06) [19]. Thus, the fit of the overall model is good. Furthermore, the standardized path coefficients are all significant at 0.01 level except for the paths from attitude to behavior intention, subjective norm to behavior intention, and perceived ease of use to Attitude. As a result, Hypothesis 2, 3 and 6 are not supported while the other hypotheses are all supported. In general, trust indicates important relationships while the relationships in Trust and TAM model are maintained in on-line shopping. The detailed discussion of the results will be presented by the order of the antecedents of intention to use and attitude in TAM model (see Figure 2, Table 2).

In general, trust indicates important relationships with the three antecedents of intention to use in TPB while the relationships in Trust and TAM model are maintained in on-line shopping. The detailed discussion of the results will be presented by the order of the antecedents of intention to use, attitude, perceived behavioral control, and subjective norm as well as the relationships with trust in TPB and TAM model (Fig. 2).

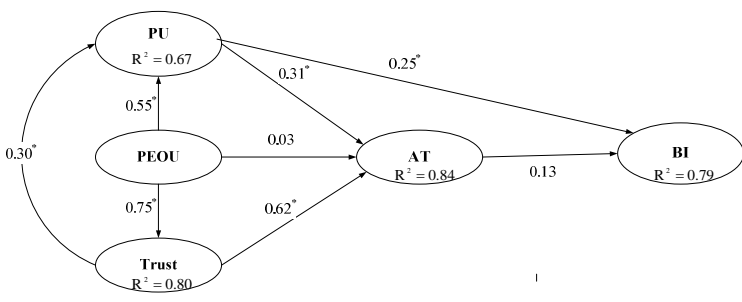

Figure 2. SEM analysis of the research model

Number on path: standardized coefficient, $R^{2}$ : coefficient of determination, ${ }^{*}: p<0.01$
Table 1. Sample demographics

\begin{tabular}{|c|c|c|c|}
\hline Measure & Item & Frequency & $\begin{array}{l}\text { Percentage } \\
(\%)\end{array}$ \\
\hline \multirow[t]{2}{*}{ Gender } & Male & 131 & 63.6 \\
\hline & Female & 75 & 36.4 \\
\hline \multirow[t]{5}{*}{ Age } & $<20$ & 24 & 11.7 \\
\hline & $20 \sim 30$ & 86 & 41.7 \\
\hline & $30 \sim 40$ & 78 & 37.9 \\
\hline & $40 \sim 50$ & 15 & 7.3 \\
\hline & $>50$ & 3 & 1.5 \\
\hline \multirow{4}{*}{$\begin{array}{l}\text { Education } \\
\text { level }\end{array}$} & $<$ High school & 6 & 2.9 \\
\hline & University & 104 & 50.5 \\
\hline & Master & 70 & 34 \\
\hline & $>$ Doctor & 26 & 12.6 \\
\hline \multirow[t]{7}{*}{ Occupation } & Finance & 2 & 1 \\
\hline & $\begin{array}{l}\text { Soldier/public } \\
\text { affairs }\end{array}$ & 36 & 17.5 \\
\hline & Information & 15 & 7.3 \\
\hline & Service & 31 & 15 \\
\hline & Manufacture & 36 & 17.5 \\
\hline & Student & 68 & 33 \\
\hline & Othes & 18 & 8.7 \\
\hline \multirow{5}{*}{$\begin{array}{l}\text { Online } \\
\text { shopping web }\end{array}$} & Yahoo & 105 & \\
\hline & Pchome & 88 & \\
\hline & Ichiba & 19 & \\
\hline & HiNet & 1 & \\
\hline & Others & 27 & \\
\hline \multirow{6}{*}{$\begin{array}{l}\text { Shopping } \\
\text { frequency }\end{array}$} & One week & 12 & 5.8 \\
\hline & One month & 62 & 30.1 \\
\hline & Three months & 55 & 26.7 \\
\hline & Half year & 39 & 18.9 \\
\hline & One year & 26 & 12.6 \\
\hline & Never & 12 & 5.8 \\
\hline \multirow[t]{6}{*}{ Cost } & $\sim 500$ & 26 & 12.6 \\
\hline & $500 \sim 1000$ & 88 & 42.7 \\
\hline & $1000 \sim 2000$ & 60 & 29.1 \\
\hline & $2000 \sim 5000$ & 23 & 11.2 \\
\hline & $5000 \sim 10000$ & 6 & 2.9 \\
\hline & $10000 \sim$ & 3 & 1.5 \\
\hline \multirow[t]{8}{*}{ Product } & $\begin{array}{ll}\begin{array}{l}\text { Product } \\
\text { woman }\end{array} & \\
\end{array}$ & 64 & \\
\hline & $\begin{array}{ll}\begin{array}{l}\text { Product } \\
\text { man }\end{array} & \text { for } \\
\end{array}$ & 51 & \\
\hline & $\begin{array}{l}\text { Electronic } \\
\text { product }\end{array}$ & 108 & \\
\hline & $\begin{array}{l}\text { Infant/young } \\
\text { product }\end{array}$ & 11 & \\
\hline & $\begin{array}{l}\text { Fashion } \\
\text { product }\end{array}$ & 36 & \\
\hline & $\begin{array}{l}\text { Livelihood } \\
\text { product }\end{array}$ & 49 & \\
\hline & Food & 18 & \\
\hline & others & 37 & \\
\hline
\end{tabular}


Table 2. Results of the hypotheses testing

\begin{tabular}{|c|l|l|}
\hline & Hypotheses & Results \\
\hline H1 & $\begin{array}{l}\text { PU has positive effect on intention to sue } \\
\text { online shopping. }\end{array}$ & Supported \\
\hline H2 & $\begin{array}{l}\text { AT has positive impact on intention to use } \\
\text { online shopping }\end{array}$ & $\begin{array}{l}\text { Not } \\
\text { Supported }\end{array}$ \\
\hline H3 & $\begin{array}{l}\text { PU has positive impact on attitude to use } \\
\text { online shopping }\end{array}$ & Supported \\
\hline H4 & $\begin{array}{l}\text { PEOU positively influences attitude to use } \\
\text { online shopping }\end{array}$ & $\begin{array}{l}\text { Not } \\
\text { Supported }\end{array}$ \\
\hline H5 & $\begin{array}{l}\text { Trust has positive effect on attitude to use } \\
\text { online shopping }\end{array}$ & Supported \\
\hline H6 & $\begin{array}{l}\text { PEOU has positive impact on PU to use } \\
\text { online shopping }\end{array}$ & Supported \\
\hline H7 & $\begin{array}{l}\text { Trust has positive effect on PU to use online } \\
\text { shopping }\end{array}$ & Supported \\
\hline H8 & $\begin{array}{l}\text { PEOU positively influences trust to use } \\
\text { online shopping }\end{array}$ & Supported \\
\hline
\end{tabular}

Intention to use on-line shopping in this research is jointly predicted by $\mathrm{PU}$ ( $\beta=0.25$, Standardized path coefficient) and attitude ( $\beta=0.13$ ), and these variables totally explain $79 \%$ of the variance on intention to use ( $R^{2}=0.79$, Coefficient of determination). Among these relationships, perceived usefulness toward the behavior is the major influence on individual's behavioral intention to use on-line shopping. The result quite conforms to the findings reported with business-based setting in prior research. Nevertheless, attitude and subjective norm do not produce significant impacts on behavioral intention to use in this research.

For the result in perceived usefulness, previous empirical studies on TAM and extended TAM have shown inconsistence for either with significant influence [20, 21] or with insignificant influence on behavioral intention to use [8]. The on-line shopping context in this study is focused on the stage of the initial adoption and voluntary use in online store. In other words, users in the on-line shopping are still in a trial and experimental manner. Users' positive perceived usefulness in using on-line shopping may immediately lead to a behavioral intention to use, rather than firstly form a favorable attitude/belief to use on-line shopping. The favorable attitude/belief to use on-line shopping is just like a time cushion before directly taking behavioral intention to use online shopping. This implies that potential users would need to take a period of time to carefully change their psychological state to adopting on-line shopping. Consequently, the attitude toward adopting on-line shopping demonstrates less significant influential power on behavioral intention to use.

Attitude is predicted by perceived usefulness ( $\beta=0.31$ ), perceived ease of use ( $\beta=0.03$ ), and trust ( $\beta=0.62$ ) with jointly $84 \%$ of the total variance explained. In that, the effect of trust on attitude is greater than PU and PEOU. This implies an important fact for researchers that traditional TAM may not completely explain the attitude/behavior toward the acceptance of on-line shopping. The result also partially validates the conclusion of Trust and TAM model by Gefen et al. [1]since the influential relationship is in terms of trust and behavioral intention to use in the Trust and TAM model. In general, trust should be necessarily included in TAM for effectively understanding the acceptance of e-ser vice.

Finally, trust ( $\beta=0.30$ ) and perceived ease of use ( $\beta=0.55$ ) both significantly influence perceived usefulness and jointly explain $67 \%$ of the total variance in perceived usefulness. The former is similar to the findings reported in the literature such as Trust and TAM model in Gefen et al. [1] and this model discussed [3]. The latter regularly corroborates most prior research on TAM in both online and general information technologies. Furthermore, perceived ease of use ( $\beta=0.75$ ) and privacy ( $\beta=0.26$ ), as discussed earlier in the literature, significantly affects trust and explains $80 \%$ of the total variance in trust. This result also conforms to Trust and TAM model $[1,8]$ in on-line shopping setting.

\section{Discussions}

There are many issues influencing user's decision in the initial adoption of on-line service. While considering both the Internet and e-vendor issues in the acceptance of on-line service, Trust and attitude with TAM model, as discussed [1, 2, 8], is well defined for its validity in exploring on-line service setting. An extension of Trust and Attitude with TAM model aims at increasing the predictive power of behavior al intention to use online shopping. Empirical data show that trust is considered as an important antecedent of the determinant of intention to use, attitude with $\beta=0.62$, and in turn, jointly contributes a high explanatory power with $R^{2}=0.79$ to behavioral intention to use on-line shopping. While compared to other models with trust and attitude with and TAM model in the literature, this extension empirically demonstrates substantial improvement in the explanatory power of behavioral intention to use on-line shopping. This result indeed provides more insight for understanding the low usage rate in online shopping.

Next, although PU ( $\beta=0.31)$ in TAM more likely representing technology-based antecedents significantly influence attitude toward the behavior; however, trust ( $\beta=0.62$ ) indicating trust-based antecedent demonstrates more positive impact on the attitude. The results indicate a fact that initial users tend to rely more on trust in non-technology features than on PU and PEOU in technology-based features 
to form their attitude toward the behavior. As a result, they jointly determine $84 \%$ of the total variance in the attitude. Moreover, trust $(\beta=0.3)$ and PEOU ( $\beta=0.55$ ) both have positive impact on PU. As we knew from previous research, PU always showed it as an important determinant of attitude in TAM and PEOU may often indicate its influence on attitude through the mediator of PU. The reason can be explained by that PEOU has been well recognized as a basic requirement for system design and deductively, its impact on attitude toward adopting information technology has increasingly become of less importance $[4,21]$. This can also be found in this study, $\beta=0.55$ for PEOU linking to PU versus $\beta=0.03$ for PEOU linking to attitude. In addition, this study indicates that trust almost plays an equally influencing role on PU as PEOU.

\section{Conclusion}

The purpose of this research is to propose an extension of Trust and Attitude with TAM model in a more comprehensive manner that jointly predicts user acceptance (initial adoption) in on-line shopping. A large sample survey from users of online shopping was employed to empirically examine this research model. There are several new findings regarding the roles of Trust, Attitude, and TAM in on-line shopping as discussed previously. These findings have important implications for both practitioners and researchers.

For practitioners, although on-line shopping is mainly presented for usage by the features of the Internet and communication technologies, however, this study shows that recognizing both technological and trust and privacy-based issues are important in increasing consumers' behavioral intention to use this service. The TAM beliefs (PU) and trust are shown to be two sets of underlying antecedents in determining behavioral intention to use, each contributing its significant influence on behavioral intention to use through a number of mediators such as attitude, perceived behavioral control, and subjective norm. This means that to effectively attract consumers to use on-line shopping, the design of on-line shopping needs to carefully pay attention to both aspects. Besides, as discussed previously, novice users tend to rely more on trust in nontechnology features than on PU and PEOU in technology-based features to develop their attitude toward the behavior. In other words, trust is more important in determining user's attitude than PU and PEOU in on-line shopping. The major trust-based concerns may include privacy protection, accuracy to declaration, and unauthorized access and so on. Then, the consumers pay attention to the individual privacy, and the plays an important role on trust.
Fundamentally, while trust is empirically identified as an antecedent of PU and in turn, an antecedent of attitude, this has some practical implications in enhancing the attitude toward using on-line shopping. On-line shopping provider should first develop trust building mechanisms for consumers in order to attract the users to accept online shopping. Examples of the online web include statements of guarantees, increased familiarity through privacy, trust, long-term customer service, and offering incentives to use. After that, PU of online shopping emerges as an important issue in attracting new users and should be carefully designed in terms of users' requirements to reflect PU of this service. Without an original consideration from trust aspect, a well-designed on-line shopping with significant PU will not well perform in attracting intentional users.

For researchers, past research on technology acceptance implicitly assumed that the success of system use is mainly dependent on technological aspect and does not consider the notion of uncertainty. However, the advent of the Internet has introduced uncertainty and risk in system acceptance and use because people often need to use the Internet to communicate, collaborate, transact, and shopping with individuals and organizations without physical face-to-face interaction. Thus, uncertainty and privacy are increasingly becoming the underlying determinant of the Internet-based system usage. Traditionally, TAM mainly focuses on the aspect of system features and thus, is insufficient in capturing the roles of individuals, organizational members, and social system in the Internet-based system usage, in particular, on-line shopping. TPB with the antecedents of attitude, perceived behavioral control, and subjective norm will be in a complementary manner to enhance the prediction capability of TAM. This study extends Trust and Attitude TAM and TPB model in exploring on-line shopping and further, empirically demonstrates relatively satisfactory results for providing more insight to this problem. This approach may be as a basis for similar research in the area.

Furthermore, subsequent research can be founded on this work. This study has focused on users who are experienced or the adoption in e-service. However, prior research has suggested that determinants of behavioral intention change in terms of users' level of experience [22, 23]. Additional research, both longitudinal and cross-sectional, is needed to examine the differences of this framework as users evolving from being aware of the e-vendor, to having experience with the e-vendor, to being continued use of the e-vendor. More research with the alternative conceptualization of trust and privacy would be useful in more understanding the roles of trust and attitude in the initial adoption of on-line shopping. 
Finally, although this study has produced some interesting results, it may still have some limitations. First, approximately $65 \%$ of the respondents are male in this empirical study. Much research has shown that gender difference could cause discrepancies in the effects of attitude, perceived behavioral control, and subjective norm on user's behavioral intention [17]. Although gender does not produce statistical significance on systematic nonresponse bias in the sample respondents, the empirical findings may be little biased for not reflecting the population distribution of gender. Next, there are approximately $95 \%$ of consumers in adopting on-line shopping in this study. Obviously, the on-line shopping is already at the mature stage of adoption. Definitely, this research is also greatly necessary for us to gain more insight on further promoting its widespread usage. But, the few consumers still concern the other limitation reason including the privacy information and system safety. However, the same respondents are randomly selected from the sample frame and thus, in a position to be well representative of the population. As a result, the empirical findings should be free for the population problem and can be widely generalized for its practical use.

\section{Acknowledgements}

This work was supported in part by the National Science Council of Republic of China under Contract No: NSC 99-2511-S-336-001 to Tsung-Li Wang and No: NSC 99-2410-H-273-005 to Ya Fen Tseng.

\section{References}

[1] D. Gefen, E. Karahanna, and D. Straub, , "Trust and TAM in online shopping: an integrated model,” MIS Q., vol. 27, pp. 51-90 2003.

[2] I.-L. Wu and J.-L. Chen, "An extension of trust and TAM model with TPB in the initial adoption of online tax: An empirical study," Inter. J. Hum. comput. Stud., vol. 62, pp. 784-808 2005.

[3] P.A. Pavlou, "Consumer acceptance of electronic commerce-integrating trust and risk with the technology acceptance model," Int. J. Electron. Commerce, vol. 7, pp. 69-103 2003.

[4] F.D. Davis, R.P. Bagozzi, and P.R. Warshaw, "User acceptance of computer technology: a comparison of two theoretical models," Manag. Sci., vol. 35, pp. 982-1002 1989.

[5] F.D. Davis, "Perceived usefulness, perceived ease of use, and user acceptance of information technology," MIS Q., vol. 13, pp. 319-40 1989.

[6] T.L. Childers, C.L. Carr, J. Peck, and S. Carson, "Hedonic and utilitarian motivations for online shopping behavior,” J. Retail., vol. 77, pp. 511-35 2001.

[7] J.W. Overby and E.J. Lee, "The effects of utilitarian and hedonic online shopping value on consumer preference and intentions," J. Bus. Res., vol. 59, pp. 1160-1166 2006.
[8] C.-M. Chiu, C.-C. Chang, H.-S. Cheng, and Y.-H. Fang, "Determinants of customer repurchase intention in online shopping,” Online Inf. Rev., vol.33, pp. 6717842009.

[9] D.-H. Shin, "Toward an understanding of the consumer acceptance of mobile wallet," Comput. Hum. Behav., vol. 25, pp. 1343-1354 2009.

[10] D.-H. Shin, "The effects of trust, security and privacy in social networking: A security-based approach to understand the pattern of adoption," Interact. Comput., vol. 22, pp. 428-438 2010.

[11] K.A. Saeed, Y. Hwang, and M.Y. Yi, "Toward an integrative framework for online consumer behavior research: a meta-analysis approach,” J. End User Comput., vol. 15, pp. 1-26 2003.

[12] S. Ganesan, "Determinants of long-Term orientation in buyer-seller relationships,” J. Mark., vol. 58, pp. 1191994.

[13] Bandura, A. (1986). Social Foundations of Thought and Action: A Social Cognitive Theory. Prentice Hall, N. J.: Englewood Cliffs.

[14] Roger, E.M. (1995). The Diffusion of Innovation, forth ed. N. Y.: Free Press.

[15] A. Bhattacherjee, "Acceptance of e-commerce services: the case of electronic brokerages," IEEE Trans. Syst., Man, and Cybern.-Part A: Syst. Hum., vol. 20, pp. 411-420 2000.

[16] V. Venkatesh and F.D. Davis, "A model of antecedent of perceived ease of use: development and test,” Dec. Sci., vol.27, pp. 451-483 1996.

[17] V. Venkatesh and F.D. Davis, "A theoretical extension of the technology acceptance model: four longitudinal field studies," Manag. Sci., vol.46, pp. 186-204 2000.

[18] Cooper, D.R. and Schindler, P.S. (2002). Business Research Methods. N.Y.: McGraw-Hill.

[19] Hair, J.F., Black, W.C., Babin, B.J., Anderson, R.E. and Tatham, R.L. (2006). Multivariate Data Analysis. N. J.: Pearson Prentice Hall, Upper Saddle River.

[20] Moore, G.C. and Benbasat, I. (1991). Development of an instrument to measure the perception of adopting an information technology innovation, Inf. Syst. Res., Vol. 2, No. 3, 192-222.

[21] Y.K. Chau, "An empirical assessment of a modified technology acceptance model,” J. Manag. Infor. Syst., vol. 13, pp. 185-204 1996.

[22] D.H. McKnight and N.L. Chervany, "What trust means in e-commerce customer relationships: an interdisciplinary conceptual typology,” Int. J. Electron. Commerce, vol. 6, pp. 35-72 2002.

[23] E. Karahanna, D.W. Straub, N.L. Chervany, "Information technology adoption across time: a cross-sectional comparison of pre-adopt ion and postadoption beliefs,” MIS Q., vol. 23, pp. 183-213 2000. 